\title{
DISCIPLINAMENTO DOS CORPOS E AS TECNOLOGIAS DISCIPLINARES EM EM NOME DO DESEJO, DE JOÃO SILVÉRIO TREVISAN
}

\author{
Pamella Oliveira*
}

\begin{abstract}
RESUMO: Considerando o crescente no tocante à literatura brasileira de temática gay, este artigo almeja contribuir para o aporte teórico e crítico em construção sobre o tema. Para isso, pretende-se fazer uma análise do romance Em nome do desejo (2001), de João Silvério Trevisan, acerca do que corresponde ao disciplinamento dos corpos, proposto principalmente por Michel Foucault (1998, 1996), que teorizou sobre a construção da sexualidade e do disciplinamento dos corpos colocados em constante vigilância a fim de garantir que não se se desviassem do padrão considerado adequado. Pretendeu-se aqui observar a forma como cada dispositivo e tecnologia de poder age em consonância com a norma pré-estabelecida de heteronormatividade.
\end{abstract}

PALAVRAS-CHAVE: Disciplinamento, Literatura homoerótica, Sexualidade.

O romance Em nome do desejo (2001), de João Silvério Trevisan, é uma narrativa essencial para a abordagem das questões acerca do disciplinamento dos corpos, da vigilância e da performatividade sexual a qual todos são submetidos, mas que afeta profundamente os homossexuais. Nele, Trevisan aborda a vida no seminário através dos olhos de Tiquinho, personagem e narrador que orienta os olhos do leitor. Sobre o assunto, Trevisan tem pro-

\footnotetext{
* Doutoranda em Estudos Literários, na linha de pesquisa Poéticas da Modernidade, na Universidade Federal de Goiás (UFG). Mestra em Estudos Literários pela Universidade Federal de Juiz de Fora (UFJF).
} 
fundo conhecimento, uma vez que passou parte da adolescência entre os muros da instituição ${ }^{1}$. No enredo, João fica conhecido como Tiquinho, devido à sua frágil estrutura física, e retorna após muitos anos ao espaço do seminário em que viveu quando jovem para tentar compreender os sentimentos desencadeados naquele lugar e, consequentemente, compreender a si mesmo.

No romance, o fio da memória é o condutor da narrativa. Ela trata, enquanto constrói o sujeito do narrador, da história de amor entre dois jovens, Tiquinho e Abel, que viviam no seminário, ambos "descobrem-se amando contra a corrente" (TREVISAN, 2001, p.7) (assim como o autor menciona na dedicatória de seu livro). Eles, no entanto, além de não serem os únicos, são levados a acreditar que seu amor é uma forma de pecado ou uma aberração. $\mathrm{Na}$ retomada da memória, são observadas dificuldades em reproduzi-la tal como aconteceu, quando, no entanto, no próprio fazer literário ela já sofreu influências dos anos passados entre o acontecimento e o momento da escrita. Essas reflexões acerca dos episódios fazem parte do processo criativo da memória que conduz o leitor pelos caminhos traçados pelo narrador, uma vez que "a memória ainda consegue refazer o clima estranho dessas penitências e arroubos espirituais". (TREVISAN, 2001, p.119)

Acerca da paixão, já na epígrafe do romance há uma questão bastante pertinente para a interpretação:

Eis a paixão segundo Spinoza: o desejo (esforço em perseverar no ser) não se define como uma paixão a mais e sim como condição de todas as paixões. Simplesmente porque é o próprio desejo que as elabora na imaginação. Daí, a alma não sofre paixão. Para Spinoza, a alma é inteiramente paixão. (do diário de Jean-Paul Carraldo). (TREVISAN, 2001, p.7)

Nela há uma referência a Spinoza, que reforça um pensamento de que toda a alma é alimentada pela paixão. Conhecer as causas da paixão, portanto, nos permite elabo- 
rar uma técnica de sua dominação. É isso o que Tiquinho, personagem e narrador do romance, faz. Ele busca de todas as formas compreender a razão de sua paixão por Abel, um amor contrário ao que é considerado certo. O jovem sofre ao tentar compreender o porquê daquele amor inclusive em passagens bíblicas em que o amor ao próximo é reafirmado. Além disso, ele aproxima Abel de Jesus Cristo, a quem era ensinado que deveria amar incondicionalmente. Esse também é um dos motivos pelo qual ele retorna à casa onde antes foi o seminário. A errância, uma constante na literatura homoerótica, o faz acessar a memória e revisitar os espaços de definição do seu caráter a fim de compreender quem se é, pois, ainda na meia idade, a busca permanece, e é ela que move o personagem na intenção de reconhecer a si mesmo.

Acerca da relação entre duas pessoas do mesmo sexo biológico, como é o que ocorre na obra em questão, elegeremos aqui o termo "homoerotismo" a fim de concordar com o que postula Jurandir Freire Costa (2002), que para justificar sua preferência por este em detrimento dos outros possíveis, defende sua preferência pelo termo enquanto elemento de uma gramática afetiva, interessada em criar laços para além da sexualidade entre seus pares. Segundo ele, "homoerotismo é uma noção mais flexível e que descreve melhor a pluralidade das práticas e desejos dos homens same-sex oriented' (p.21). A escolha deste vocábulo especificamente, portanto, pressupõe a existência de uma relação além do carnal, que encontra razão de ser também nas atenções afetivas.

A questão identitária em torno do saber-se quem se é de fato se mostra latente no romance ao dominar adolescentes que não sabem o que fazer com os desejos de seus corpos, pois que este lhes é negado de todas as formas. Essa questão fica ainda mais presente quando se trata do desejo homoerótico. As dúvidas e os questionamentos acerca de sua identidade que se crê indevida e inadequada é um dos alicerces sobre os quais se pautam a obra. Tiquinho descobre-se apaixonado por seu companheiro de seminário, Abel e, dessa forma, entre a devoção quase santa, a atração física e o desejo carnal ocorrem inúmeros encontros e questionamentos acerca da relação desenvolvida por ambos. 
Ainda nas páginas iniciais do livro, há uma planta baixa da arquitetura do seminário. Nela, podemos observar a disposição dos quartos, dos ambientes de estudo e refeição, lugares destinados aos trabalhos manuais, às orações etc. É possível perceber que, de acordo com a arquitetura, alunos maiores não têm livre acesso aos alunos menores e viceversa. Além disso, a disposição dos espaços é milimetricamente pensada no sentido de disciplinamento dos corpos. Um exemplo disso é que os alunos menores ficam mais próximos, por exemplo, do campo de futebol e do galpão de recreios, lugares que remetem ao lúdico; enquanto os alunos maiores, julgados mais maduros, ficam localizados nas proximidades do chiqueiro, onde ocorrem os trabalhos, e da capela, o local de oração, pressupondo mais seriedade em suas incumbências. A disposição dos espaços é, ao mesmo tempo, facilitadora e impeditiva do contato entre os corpos. Se por um lado, a construção panóptica do ambiente é uma dificultadora das possíveis transgressões; por outro lado, o excesso de espaços obscuros é também um convite à transgressão disciplinar.

Há, nessa divisão, uma oposição binária entre os espaços localizados no alto terreno e de planta baixa, em que se nota um contraste entre o sagrado e profano. Os espaços do terreno em declive eram mais ermos e, consequentemente, possibilitavam os encontros sexuais entre os garotos, eram lugares sujos e úmidos, como a bolaria, o depósito e o chiqueiro, ambientes que fazem referência ao que ocorria ali, como um reflexo da atividade sexual entre meninos associada a algo impuro e infecto. Como o lugar em que Abel e Tiquinho podiam se encontrar que, segundo o narrador aponta:

Apesar de limparem o espaço e deixarem um toco de vela aceso, não podiam evitar presenças estranhas. Muitas vezes, enquanto Tico e Abel se beijavam, esfregavam e resfolegavam, os ratos passavam guinchando e atropelando seu amor. Desistiram do porão definitivamente, na noite em que Abel quase pisou numa cobra coral já em posição de ataque. (TREVISAN, 2001, p.190-191)

Em contrapartida, os espaços do terreno em aclive são considerados mais próximos de Deus e, por isso, sagrados, como a capela, que é o ponto mais alto da planta em questão. 
A distribuição dos corpos, segundo postula Michel Foucault, é o primeiro passo para implantar o disciplinamento de forma efetiva. Assim, ele aponta a distribuição das edificações educacionais como forma de servirem aos fins iniciais e, ao mesmo tempo, impedir a relação íntima entre os corpos ali dispostos: "Lugares determinados se definem para satisfazer não só à necessidade de vigiar, de romper com as comunicações perigosas, mas também de criar um espaço útil” (1996, p.132), para isso, há o quadriculamento, método ainda julgado insuficiente pelo filósofo francês para peneirar os disciplinados.

Para falarmos de um espaço como o do seminário, assim como muitos outros compostos em que há uma convivência maciça entre membros do mesmo sexo, urge a retomada e a elucidação do termo "homossociabilidade" cunhado por Eve Sedgwick (1985). Segundo a autora, trata-se de uma prática comum em estruturas sociais entre pessoas do mesmo sexo, considerando desde a solidariedade e a colaboração, até a rivalidade e a competição entre os membros do grupo, sem excluir, no entanto, a possibilidade de furtivos relacionamentos sexuais entre eles.

Esses relacionamentos ocorriam na surdina, uma vez que, acredita-se, a convivência próxima e íntima desperta desejos sexuais que do contrário permaneceriam escondidos. Esses relacionamentos ocorriam em uma fresta mínima encontrada no limite tênue entre o companheirismo dos colegas de seminário e o que os próprios regulamentos apontavam como uma "amizade particular", em que essa pressupunha um contato além do permitido entre os garotos. Além da questão preconceituosa socialmente incutida nas relações entre homossexuais, há ainda a luta pela tentativa baseada no discurso bíblico de anular os corpos, em uma busca incessante por calar os desejos carnais com tentativas (muitas vezes infrutíferas) de saciar os corpos apenas com as disciplinas impostas a eles.

Contraditoriamente a isso, havia ainda a tentativa de "forjar homens com $\mathrm{H}$ maiúsculo - e com isso queria dizer "homens-macho”" (TREVISAN, 2001, p.96). A construção de um jovem que correspondesse ao imaginário ideal de virilidade era uma função do seminário. As crenças de que "homem de verdade cheirava a suor; aliás, homem devia ter 
"cheiro de porra"' (p.61) eram elementos separatistas entre aqueles que condiziam à heteronormatividade e aqueles que divergiam dela, motivo, aliás, que fazia com que aqueles que usavam talco e cheiravam bem ficassem conhecidos como "frescos". Sobre isso, o narrador relembra:

A preocupação do Reitor com a virilidade dos meninos levava-o a atitudes extremas, como no caso de seu predileto Sapinho, a quem obrigou a passar por uma dieta de sangue de boi em jejum, todas as manhãs, durante dois meses - a fim de "robustecer o sangue e o temperamento", como dizia. Para ele, afinal, o físico moldava o caráter. Daí seu cuidado muito especial com o desenvolvimento físico dos adolescentes. (p.97)

As chamadas amizades particulares ocorriam nos espaços de homossociabilidade, isto é, nos lugares em que os garotos poderiam ficar sozinhos e, de preferência, sem a vigilância hierárquica dos padres e reitores. Esses lugares eram o campo de futebol, a bolaria, nos banheiros e até mesmo nos quartos de dormir durante a madrugada. Os jovens apaixonados também conseguiram promover furtivos encontros durante os horários de oração, o que aparece como uma dupla transgressão à norma: além do encontro íntimo, o fizeram em tempo destinado ao louvor do que era sagrado, colocando no mesmo plano, assim, o profano e o sagrado.

O campo de futebol conta, nesse caso, com um papel duplo no desdobramento das relações, enquanto funciona ainda como um lugar de consolidação da produção dos corpos, atléticos, másculos e viris, também era um local livre que facilitava o contato corporal entre os alunos; mas também era um espaço de punição e de violência, uma vez que era onde ocorria o temido jogo do garrafão, cuja principal função era "formar homens rijos ou, como se dizia, homens de fibra" (TREVISAN, 2001, p.48). Nele, os meninos julgados merecedores de uma lição (que, nesse caso, pertenciam a esse grupo dos que destoavam do comportamento heteronormativo que se espera dos garotos) passavam por uma espécie de corredor em formato de funil enquanto eram bombardeados por lenços endurecidos com cola branca.

Quando finalmente conseguia entrar, a vítima tomava uma surra de lambadas de variados quilates de agressividade. Como não se podia 
xingar de "fresco" e "filho-da-puta", ecoava em coro a saudação ritmada: ma-ri-qui-nha, ma-ri-qui-nha. A seguir, o jogo recomeçava, com outro pegador e novas energias. (...) As vítimas eram quase sempre as mesmas; eram sempre as mesmas vítimas, portanto, que tomavam uma surra de nós com cola dura, o que equivalia a uma saraivada de pedras a açoitar o corpo. (p.50)

Um gesto impiedoso de violência pelo qual os garotos tidos como "fora da curva" eram obrigados a tolerar, e sobre o qual os padres faziam vista grossa, também em uma forma de serem coniventes com esse tipo de punição para aqueles que se diferenciavam do que era aceito como padrão convencional.

Essa forma de comportamento é um dos destaques feitos por Guacira Louro em seu texto "Pedagogias da sexualidade" (2010), no qual ela destaca a formação da criança do sexo masculino. Segundo ela, uma constante no processo, ao qual denomina de "produção do menino", é o tolhimento do prazer como uma constante, ao mesmo tempo que há o rendimento da violência. Esse comportamento se dá, ela afirma, pela busca de uma masculinidade forjada em três pilares: esporte, competição e violência consentida. Elementos considerados basilares para a consolidação do menino como uma pessoa forte, máscula e viril. Isso se dá sob a incessante observação e o estabelecimento de critérios para que eles (e também as meninas, porém sob outros processos, como ela aponta) não se afastem daquilo que é considerado a norma.

Mesmo na tentativa de fazer o corpo condizer à norma heteronormativa, no entanto, o corpo se trai, no momento em que sua performance não condiz com aquela exigida pelo padrão normativo. Nesse momento de deslize, o olhar inquisitivo da vigilância está a postos. A partir desses controles de conduta, o grupo de meninos do seminário é batizado de "Passarada", devido aos apelidos com nomes de pássaros, batizados de forma pejorativa de aludir aos trejeitos efeminados e finas vozes dos integrantes do grupo. O grupo era o alvo mais buscado quando os meninos se reuniam para o famoso (e doloroso, como aponta o personagem) “jogo do garrafão”. O apelido é uma forma de coerção social amplamente utilizado, pois marca as pessoas de comportamento dissonante do esperado (ERIBON, 
2008). Assim, uma vez marcados, eles serão facilmente vigiados, excluídos e observados por todos.

O olho panóptico não falha em punir a todos pelos desvios da conduta considerada adequada. Isso faz com que aqueles que têm a sexualidade desviada da norma mantenham-se em constante alerta, pois, no panóptico, embora todos os vigiados saibam-se observados de cima para baixo, esse dispositivo conta também com a observação horizontal, isto é, entre iguais, de onde não é possível identificar os olhos vigilantes. Foucault (1996), como teórico desta questão, aponta que o fato de saber da possibilidade de ser vigiado já é o suficiente para induzir o comportamento desejado dos corpos. Isso, no romance, é atestado pela preocupação dos padres em deixar que os meninos se relacionem em pares sugerindo que mantivessem sempre em grupos de três, pois assim haveria sempre um outro vigilante, que ajudaria a manter a disciplina:

Muito menos, apegar-se demasiadamente uns aos outros, porque o amor de Deus era contrário ao egoísmo de amizades que, por fechadas, acabava, criando ocasião para o pecado. "Se um não é bom, convém evitar dois. O bom é sempre três", sentenciava o velho Reitor, com o dedo em riste e os lábios trêmulos a se moverem mais do que pediam as palavras. Segundo ele, devia-se manter contínua vigilância, com a mortificação de todos os sentidos. (TREVISAN, 2001, p.76)

A homofobia é institucionalizada pela escola como obstáculo à manifestação da sexualidade na tentativa de mantê-la em segredo. Nesses espaços, como aponta Louro (2010), só há lugar para o homossexual se ele se mantiver em segredo, imperceptível, "no armário", do contrário é rechaçado e se torna uma grave ameaça à sexualidade dos pares. A simbologia do armário é mantida até mesmo entre o casal apaixonado. Ao perceber os inúmeros comentários sobre sua relação, Abel propõe a Tiquinho um plano que pretende “desfazer sua fama de mariquinha” (TREVISAN, 2001, p.178) e torná-lo homem, e, para isso, ele deveria se afastar do grupo conhecido como Passarada e praticar esportes. A homofobia, em uma sociedade patriarcal, surge como elemento chave para a valorização do 
heteronormativo, exaltando a norma a ser seguida, enquanto alija toda e qualquer manifestação sexual que divirja disso. Assim, de acordo com o que propõe Eve Sedgwick (1985, p.4): "Nevertheless, it has yet to be demonstrated that, because most patriarchies structurally include homophobia, therefore patriarchy structurally requires homophobia" (grifo da autora).

Como origem da homofobia, pode-se apontar a presença constante da misoginia, isto é, o ódio ou aversão a mulheres e meninas, manifestada de inúmeras formas como a violência machista a humilhação, a discriminação, a marginalização e a objetificação sexual da mulher, odiando tudo o que lhes diz respeito. Isso pois embora Tiquinho fosse constantemente humilhado por sua relação com Abel, o mesmo não acontece com este, pois socialmente exercia o papel de macho na relação, enquanto aquele era "sua mulherzinha". Isso ocorria, pois a relação era claramente dividida nos termos heterossexuais, como se eles exercessem funções heteronormativas, quais sejam, Abel era o macho, enquanto Tiquinho era sexualmente sua fêmea: “ 'Chupa', ordenava Abel. 'Não', balbuciava um Tiquinho inseguro. 'Se você gosta de mim, então chupa' - insistia Abel”' (TREVISAN, 2001, p.194).

Os mecanismos de disciplinamento dos corpos habitam diversas ocasiões do romance, como na reorganização do tempo, do espaço e, consequentemente, dos corpos. Segundo Michel Foucault, há três principais novidades no quesito das técnicas disciplinares que surgiram na passagem do século XVII para o XVIII:

A escala, em primeiro lugar, do controle: não se trata de cuidar do corpo, em massa, grosso modo, como se fosse uma unidade indissociável mas de trabalhá-lo detalhadamente; de exercer sobre ele uma coerção sem folga, de mantêlo ao nivel mesmo da mecânica — movimentos, gestos atitude, rapidez: poder infinitesimal sobre o corpo ativo. O objeto, em seguida, do controle: não, ou não mais, os elementos significativos do comportamento ou a linguagem do corpo, mas a economia, a eficácia dos movimentos, sua organização interna; a coação se faz mais sobre as forças que sobre os sinais; a única cerimônia que realmente importa é a do exercício. A modalidade enfim: implica numa coerção ininterrupta, constante, que vela sobre os processos da atividade mais que sobre seu resultado e se exerce de acordo com uma codificação que esquadrinha ao máximo o tempo, o espaço, os movimentos. (1996, p.126, grifos meus) 
Essa ininterrupta vigilância se dá como forma de servir à norma utilitarista, segundo aponta Foucault (1996). Com o tolhimento dos prazeres dos corpos, é possível, acredita-se, que os sujeitos fiquem mais úteis ao trabalho, sem distrações. A narrativa apresenta a rotina diária do seminário de forma que o cronograma apresentasse funções que preenchiam cada uma das possíveis brechas entre as atividades principais, preenchendo todos os tempos minimamente ociosos com oração e horários de estudo-obrigatório. Isso se dá, pois o dobramento dos corpos sob as regras de comportamento e disciplina aumentaria, dessa forma, exponencialmente a sua produção, tornando-os corpos dóceis.

Consoante a isso, também Georges Bataille no "Estudo IV" de sua obra O Erotismo (1987) aponta que, embora inicialmente pareçam opostos, erotismo e santidade têm traços comuns que os unem em torno de uma mesma intenção. O texto, fruto de uma conferência do autor no Collège Philosophique no ano de 1955, prenuncia a condução das disciplinas enquanto elementos moldadores de corpos forjados essencialmente para o trabalho. A proximidade do erotismo e da santidade, ele aponta, posteriormente a fim de mostrar como ambos deflagram também a solidão, são experiências extremas, e o disciplinamento dos corpos, portanto, não permite experimentações extremas. O trabalho braçal e o preenchimento da grade de atividades de forma que não haja nenhum espaço livre previa, portanto, segundo concordam Bataille (1987) e Foucault (1988), que as mentes se mantivessem extremamente ocupadas e que até o tempo de descanso fosse escasso para que não tivessem tempo hábil para pensar nos desejos que enfraqueceriam o corpo para o trabalho.

Nesse caso, a utilidade tem a ver com a correspondência de uma performance sexual esperada. A elaboração criteriosa e exaustiva do tempo previa que o corpo fosse voltado para o desenvolvimento da força física através de exercícios para que, assim, a força política (e sexual) não pudesse se desenvolver, pois “a disciplina organiza uma economia positiva; coloca o princípio de uma utilização teoricamente sempre crescente do tempo: mais exaustão que emprego; importa extrair do tempo sempre mais instantes disponíveis e de cada instante sempre mais forças úteis" (FOUCAULT, 1996, p.140). 
O projeto por trás desse disciplinamento sem folga ao qual é incutido os corpos intenciona que a disciplina maciça possa uniformizar os corpos e, assim, manter todos os alunos dentro do mesmo padrão, aquele considerado aceitável. A massificação dos corpos pressupõe uma equidade entre si, desconsiderando, portanto, a subjetividade dos indivíduos. O sujeito, no entanto, toma consciência de si a partir do investimento de disciplinas que agem sobre ele. Sobre isso, Louro ainda aborda a forma como diferentes instâncias sociais exercem suas forças sobre a sexualidade e o gênero das crianças. Tais como dispositivos de poder que culminam em tecnologias de autodisciplinamento e autogoverno. (FOUCAULT, 1993 apud LOURO, 2010)

A constante e redobrada vigilância sobre os corpos na tentativa de tolher a sexualidade, contudo, consegue apenas limitar sua manifestação tornando-a um experimento de desejo sem que se possa evitar, todavia, que a força da disciplina aja sobre aqueles corpos dobrando-os sob suas normas:

Já que raramente os pintos podiam se mostrar às claras, um pinto entrevisto em estado rígido era algo delicioso como um feriado e provocava autêntica estupefação. (...) Mas havia casos em que, por força do escrúpulos cristãos, a repulsa se impunha sobre a atração e o amor vestia máscaras temíveis. (...) É que a atração gerava o movimento contrário, mas não se diluía nele. Ao contrário, alimentava-se no desejo e crescia até se tornar insustentável. (TREVISAN, 2001, p.73)

Sobre o disciplinamento, Foucault (1996) ainda elucida as articulações disciplinatórias às quais os corpos são submetidos. Na composição das forças, a ordem não precisa ser dita constantemente, uma vez que as táticas e os mínimos sinais pré-estabelecidos pressupõem a continuidade das disciplinas (como o olhar repressor, por exemplo), coagindo o subordinado à obediência dos comandos já enraizados.

A partir da tríade sugerida por Foucault dos pilares da vigilância a partir dos postos de observatório de ideias, quais sejam, observação, registro e treinamento, os responsáveis pelo seminário buscavam cercar os jovens de todo tipo de intervenção externa, considerando as atividades mundanas muito profanas para aqueles corpos santos. A exemplo 
a leitura prévia pela qual passavam todas as correspondências recebidas pelos meninos do seminário: "A autoridade dos superiores expressava-se, por exemplo, no direito de ler todas as cartas recebidas pelos seminaristas e, eventualmente, efetuar censuras antes de entregálas a seus destinatários" (TREVISAN, 2001, p.34).

Justamente devido à tentativa de docilizar os corpos, surgem duas antigas estratégias antigas utilizadas há muito no cristianismo: o silêncio e a confissão. $\mathrm{Na}$ narrativa memorialística de Tiquinho, ele rememora que o retorno ao seminário após o período de férias escolares pelo qual os meninos passavam no fim do ano letivo era marcado por um rigoroso silêncio imputado aos jovens na intenção de livrá-los do mal. Segundo Guacira Louro (2010), o corpo escolarizado é capaz de manter-se sentado por horas a fio, uma vez que é treinado para manter-se em silêncio ou em uma mesma posição. Além de serem constantemente induzidos à confissão, prática sobre a qual Foucault ressalta que:

A confissão é um ritual de discurso onde o sujeito que fala coincide com o sujeito do enunciado; é, também, um ritual que se desenrola numa relação de poder, pois não se confessa sem a presença ao menos virtual de um parceiro, que não é simplesmente o interlocutor, mas a instância que requer a confissão, impõe-na, avalia-a e intervém para julgar, punir, perdoar, consolar, reconciliar; (...) enfim, um ritual onde a enunciação de si, independentemente de suas consequências externas, produz em quem a articula modificações intrínsecas: inocenta-o, resgata-o, purifica-o, livra-o de suas faltas, libera-o, promete-lhe a salvação. (1988, p.70-71).

O corpo é uma máquina adestrável. Nos ambientes escolares, urge de forma pungente o disciplinamento desses corpos, pois há a pressão em moldá-los de forma a corresponder ao que é considerado correto. Segundo aponta Foucault (1988), o poder disciplinar pretende adestrar como forma de se apropriar melhor dos corpos, condicionando-os a caminhos pré-estabelecidos, evitando de todas as formas que eles se desviem. Uniformizados, então, sem contar com a possibilidade de escolha, as massas respondem melhor às utilizações dos corpos, que pretendem servir a um ideal utilitário, tomando-os como instrumentos de ideais. 
Em vez de dobrar uniformemente e por massa tudo o que lhe está submetido, separa, analisa, diferencia, leva seus processos de decomposição até às singularidades necessárias e suficientes. "Adestrar" as multidões confusas, imóveis, inúteis de corpos e forças para uma multiplicidade de elementos individuais - pequenas células separadas, autonomias orgânicas, identidades e continuidades genéticas, segmentos combinatórios. (FOUCAULT, 1988, p.153)

Na biopolítica, o corpo do sujeito, aponta Mendes (2006), é impelido a falar de si para se governar e ser governado. A confissão, dessa forma, é um dispositivo de poder utilizado para medir o pensamento dos seminaristas, mas que também funciona para instiga-los a conhecer ainda mais profundamente o próprio corpo. Tiquinho, ao transcrever à mão o livro $A$ pérola das virtudes, como forma de penitência por ter se masturbado, sente nascer em si o desejo ainda mais latente:

Mas as bonitas palavras do livro, que douravam a castidade com um brilho verdadeiramente convincente, tiveram também o efeito de tornar mais fascinante o pecado correspondente, que acabou sendo praticado com insistência ainda maior. (TREVISAN, 2001, p.119)

Segundo destaca Mendes, com base na teoria de Foucault, o corpo é um ente moldável pela "ação de poder que compõem tecnologias políticas específicas e históricas" (2006, p.168), ao contrário do sujeito cuja existência não é considerada. Assim, a observação dos corpos como mecanismo de controlar a formação dos sujeitos aparece inúmeras vezes no romance de Trevisan. À exemplo, a vistoria do reitor em busca dos "sintomas" de que eles estariam praticando a masturbação, o que atestaria pensamentos impuros.

Quanto à masturbação, que continuava rigorosamente controlada, o Reitor assim se manifestava, em suas vistorias: "Deixa eu ver os peitos. Eta, peito inchado. Masturbação demais, rapaz. Vê se toma jeito. Peito inchado em homem é feio". Já o diretor espiritual era diferente: relacionava-se e cuidava dos seus Menores como se levitasse desde o início e os chamasse para o alto, consigo. Usava estratagemas poéticas: no caso da masturbação, amarrava fitinhas de várias cores no membro genial dos meninos mais reincidentes. As várias cores correspondiam à gravidade das fases masturbatórias. Para um controle que ele fazia pessoalmente e com rigor, obrigava os garotos a dar um nó na fitinha, a cada nova masturbação. Assim, 
acompanhava de perto a atividade pecaminosa dos pequenos, com muita imaginação. (TREVISAN, 2001, p.100).

No trecho, o narrador aponta para a crucial diferença entre a abordagem dos mentores religiosos, mas que, no entanto, culminam no mesmo objetivo: ambos pretendem ter acesso ao corpo dos jovens, alegando o interesse na higiene e na verificação dos considerados pecados. Entretanto, o interesse pelos corpos impúberes fica claro, ao que o narrador aponta que

Aí, mandava que tirassem a roupa e os examinava vigorosamente, para verificar sua saúde e certificar-se de que observavam as regras de higiene que lhes prescrevia. (...) Fazia tudo isso com extrema objetividade, mas seus gestos profissionais não conseguiam ocultar intenções subjacentes que os alunos mais sensíveis captavam. De modo que não era incomum os exames terminarem em mal contidas ereções dos pequenos membros alvoroçados pelo contato "tépido" e experiente do querido Reitor. (TREVISAN, 2001, p.97).

Tornando visível, assim, o interesse homoerótico da parte daqueles que, em tese, deveriam zelar pela manutenção da anulação dos desejos sexuais.

As sanções normalizadoras garantem o sucesso do poder disciplinador, elas são exercidas mediante micropenalidades. Essa mecânica do poder não se trata, no entanto, de modificar o ato, mas de exaltar o detentor do poder. Disso decorrem, por exemplo, as avaliações escolares, uma vez que há de se lembrar que a vigilância e o disciplinamento são imputados a toda a sociedade e não apenas àqueles que desviam da norma. $\mathrm{O}$ binarismo entre gratificação e recompensa age de forma a possibilitar a classificação dos indivíduos, uma vez que esse nivelamento entre o mais castigado e o mais recompensado institui e gratifica a "norma" enquanto rechaça aquele que não comunga dela. A própria ideia de norma é um princípio de coerção, pois institui quem está nela e quem lhe diverge.

Acerca da imaginação e sua relação com o erotismo, evoco aqui o texto "Os reinos de Pã”, da autoria de Octavio Paz (1994), que ao analisar as relações entre sexo, amor e erotismo destaca a natureza distinta entre eles, embora essa tríade faça parte de um único fenômeno, a vida. O sexo, o item mais antigo desse tripé e, consequentemente, erotismo e amor derivam dele. Dessa forma, ao falar em sexualidade, fala-se em leis naturais, ciência, 
biologia, multiplicação de células, átomos, é nessa seara que habita a reprodução humana. O erotismo, por outro lado, é exclusivamente humano, pois trata-se da sexualidade transfigurada pela imaginação e pelo desejo por um parceiro que pode ser, por exemplo, apenas no imaginário. $\mathrm{O}$ autor aponta que enquanto o sexo é submetido às regras sociais, o erotismo é servidor da vida e da morte.

Ele analisa ainda o erotismo e as práticas religiosas, relação em que, na intenção de domar o sexo, criou-se uma miríade de regras instituídas na abstinência e permissão. Ambas são contraditórias e tornam-se prescrições apoiadas na ciência e também na manutenção da higiene, em que comungam prazer e morte. Segundo Paz (1994), a abstenção e a permissão do sexo podem ser periódicas e alternadas ou mesmo absolutas, como é o caso dos monges e das freiras. No romance, no entanto, essas práticas são vigiadas sob vistas grossas quando exercidas em ambientes lúgubres ou quando o ator da mediação sexual é o próprio mentor espiritual. O erotismo religioso, como aponta Paz, inverte radicalmente o processo sexual, expropriando os imensos poderes do sexo para fins contrários à reprodução.

\section{Considerações finais}

No romance de Trevisan, como é comum nos romances de formação, o narrador conduz o leitor a fim de justificar sua própria constituição enquanto sujeito. Todas os elementos abordados, acerca da confissão, disciplina, vigilância e do dobramento dos corpos são elucidadas enquanto fortes elementos formadores daquele indivíduo. Ao longo do romance, embora Tiquinho parecesse seguro e convencido de sua sexualidade, ainda no início da obra temos conhecimento de que ele cresceu, estudou, se casou e teve filhos, fato que, a partir de uma interpretação heteronormativa, faz o leitor crer que ele não tenha conseguido assumir socialmente sua sexualidade. As técnicas de coerção da sexualidade funcionaram, portanto, em seu jovem corpo.

Uma vez que ele não tenha conseguido se desvencilhar do que se é de fato, o faz, anos depois, retornar à casa em que cresceu. Agora condicionado a buscar as marcas do que o 
fizeram tomar cada uma daquelas decisões, ele narra sua saga seguindo o formato dos compêndios educacionais do catecismo empregado na doutrinação da Igreja Católica para com seus fiéis a partir de perguntas e respostas. Dessa forma, ele elucida ainda mais a sua formação enquanto ex-seminarista, atuando quase como um crítico social de si mesmo, enquanto levanta importantes questões do disciplinamento dos corpos a partir de técnicas e dispositivos de coerção, punição e vigilância constantes.

A obra de João Silvério Trevisan encontra importância estética enquanto discussão de questões absolutamente contemporâneas como a discussão política em torno da literatura de cunho homoerótico. $\mathrm{O}$ autor consegue, de forma afirmativa, marcar seu espaço no bojo da literatura contemporânea não apenas como criação sobre gays e para gays, mas com elementos estéticos e teóricos dignos de análise profunda com elementos ricos as quais apenas este artigo não daria conta de abarcar de forma adequada.

A atual retomada dos espaços de fala antes negados aos integrantes de grupos minoritários é uma das grandes conquistas desses tempos sombrios. Se por um lado o conservadorismo vem ganhando força e se destacando de formas até então inimagináveis para o século XXI, os movimentos sociais nunca estiveram tão em voga, tomando lugares que antes não poderiam ser ocupados por gays. A transgressão dos dispositivos de poder é, como afirma Giorgio Agamben em seu "Elogio da Profanação" (2007), a tarefa política das próximas gerações. Por isso, analisar de forma crítica a literatura homoerótica mostra-se cada vez mais urgente, a fim de reestabelecer um cânone literário que os abarque enquanto obra merecedora de destaque antes por suas elaborações estéticas, do que apenas por sua temática.

\title{
BODY-DISCIPLINING AND DISCIPLINARY TECHNOLOGIES IN EM NOME DO DESEJO, BY JOÃO SILVÉRIO TREVISAN
}

\begin{abstract}
Taking into account the growth in the gay-themed Brazilian literature, this article aims to contribute to the theoretical and critical basis of the subject. In order to do this, it aims to analyze the novel Em nome do desejo (2001), by João Silvério Trevizan, and the matter of the body-disciplining, as posed mainly by Michel Foucault $(1998,1996)$, who theorized about the construction of sexuality and the process of disciplining the
\end{abstract}


bodies through constant vigilance to guarantee they do not deviate from the established behavior standard. In the present article what was observed was how each device and power technology works in consonance with the established heteronomativity pattern.

KEYWORDS: Disciplining, Homoerotic literature, Sexuality.

\section{REFERÊNCIAS}

AGAMBEN, Giorgio. Elogio da Profanação. In: Profanações. São Paulo: Boitempo, 2007. p. 65-80.

BARCELLOS, José Carlos. Literatura e homoerotismo em questão. Rio de Janeiro: Dialogarts, 2006.

BATAILLE, Georges. O erotismo. Trad.: Antonio Carlos Viana. Porto Alegre: L\&PM, 1987.

BUTLER, Judith. Corpos que pesam: sobre os limites discursivos do sexo. In: LOURO, Guacira Lopes (Org.). O corpo educado: pedagogias da sexualidade. Belo Horizonte: Autêntica, 2010. p. 151-172.

COSTA, Jurandir Freire. Introdução. In: A inocência e o vício: estudos sobre o homoerotismo. Rio de Janeiro: Relume-Dumará, 1992. p.105-126.

ERIBON, Didier. Reflexões sobre a questão gay. Rio de Janeiro: Companhia de Freud, 2008.

FALCÃO, Maria de Fátima L.V.; CAMARGO, Flávio Pereira. "Eu amo Abel como a mim mesmo e o amor de Jesus é o mesmo dentro de nós": a dessacralização do divino na obra Em nome do desejo, de João Silvério Trevisan. In: MITIDIERI, A.L.; CAMARGO, F.P. (Orgs.) Literatura, homoerotismo e expressões homoculturais [online]. Ilhéus, BA: Editus, 2015. p. 165-189. Disponível em: books.scielo.org/id/5j38w/pdf/mitidieri-978857455442607.pdf. Acesso em: 25 mai 2017.

FOUCAULT, Michel. Vigiar e punir: nascimento da prisão. Tradução de Raquel Ramalhete. $13^{a}$ Edição. Petrópolis: Vozes, 1996.

. História da sexualidade I: a vontade de saber. Tradução de Maria Thereza da Costa Albuquerque, J. A. Guilhon Albuquerque. Rio de Janeiro: Graal, 1988.

MENDES, Cláudio Lúcio. O corpo em Foucault: superfície de disciplinamento e governo. Revista de Ciências Humanas, Florianópolis, n. 39, p. 167-181, abr. 2006.

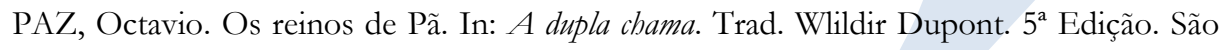
Paulo: Siciliano, 1994. p.11-29.

SEDGWICK, Eve K. Between men: English Literature and Male Homosocial Desire. New York: Columbia University Press, 1985.

SILVA, Tomaz Tadeu. A produção social da identidade e da diferença. In: . (Org.). Identidade e diferença: a perspectiva dos estudos culturais. Petrópolis: Vozes, 2000. p. 73-102 
TREVISAN, João Silvério. Em nome do desejo. Rio de Janeiro: Record, 2001.

Recebido em: 16/09/2017.

Aprovado em: 09/12/2017. 